\title{
NUEVOS USOS RESIDENCIALES EN EL ESPACIO RURAL DE CASTILLA Y LEÓN ${ }^{1}$
}

\author{
Milagros Alario Trigueros \\ Fernando Molinero Hernando \\ Erica Morales Prieto \\ Departamento de Geografía. Universidad de Valladolid \\ alario@fyl.uva.es, molinero@fyl.uva.es, ericamoralesprieto@hotmail.com
}

\section{RESUMEN}

El poblamiento de Castilla y León, antiguo y denso, es hoy disfuncional. Las transformaciones productivas desde mediados del $\mathrm{s}$. XX han provocado un vaciamiento poblacional y una discordancia entre el número de habitantes residentes y el de núcleos. Muchos de éstos, en riesgo de desaparición, se han mantenido gracias a la renovación de unas casas y a la construcción de otras.

Ello se debe a los nuevos pobladores, escasos en número, pero de gran valor cualitativo, y a la masiva llegada de residentes temporales, que, sin aparecer en las estadísticas, aportan vida económica y social, y constituyen la clave del mantenimiento de los pueblos, frente a la recesión demográfica permanente, propia del ámbito rural de Castilla y León.

Palabras clave: nuevos usos residenciales, espacio rural, Castilla y León.

\section{ABSTRACT}

Today the settlement of Castilla y León, old and dense, is dysfunctional. Productive changes since the mid XX century have led to depopulation and a disharmony between the number of people living in rural areas and the number of villages. Many of these, at risk of disappearing, are maintained thanks to the renovation of houses and the construction of others. This is due, on one hand, to new settlers, few in number, but with large qualitative value, and, on the other hand, to the massive arrival of temporary residents, who, without appearing in the statistics, provide

Fecha de recepción: noviembre 2012.

Fecha de aceptación: diciembre 2013.

1 Trabajo elaborado con el apoyo del Proyecto I+D+i, de Ref. CSO2012-39564-C07-01, sobre Paisajes patrimoniales de la España interior septentrional y occidental, financiado por el MINECO. 
economic and social life, and are the key to the maintenance of villages, against demographic and permanent recession, characteristic of the rural areas of Castilla y León.

Key words: new residential uses, rural space, Castilla y León.

\section{INTRODUCCIÓN}

Existe una clara disparidad entre la población y el poblamiento rural de Castilla y León. De entrada, se constata una dinámica demográfica regresiva desde mediados del siglo XX, con algunos cambios puntuales en las últimas dos décadas. Sin embargo, en los pueblos se ha mantenido el número de entidades y hasta ha crecido el número de viviendas.

Esta evidencia nos permite plantear la hipótesis de que el uso residencial permanente de los pueblos no es ya su única función, por más que constituya la razón de ser del mantenimiento de la densa red de núcleos rurales. De hecho, gran parte de la dinámica económica -como la prestación de servicios y el desarrollo de la construcción- están directamente relacionadas con los usos temporales del territorio.

El estudio se apoya en el análisis de los Censos de Población y Viviendas de 1991 y 2011, para la valoración de la dinámica demográfica y la evolución del número y tipo de viviendas, y en el Censo de 2001, para la caracterización de la población vinculada en los municipios rurales, la cual no hemos podido utilizar en el Censo de 2011, por cuanto estos datos sólo están disponibles para municipios mayores de 10.000 habitantes. Hemos completado los datos demográficos con el análisis de los nomenclátores de los mismos años, para el estudio de las entidades, y hemos utilizado algunos otros datos más recientes (Padrón de 2013) para poder comparar las variables demográficas con otras económicas del año 2013, especialmente las referentes a la población ocupada por sector y rama económica en septiembre de 2013, según el censo de cotizantes a la Seguridad Social en cada municipio de Castilla y León.

Fundamental para nuestro análisis han sido los datos de la Encuesta de Infraestructuras y Equipamientos Locales de 1995 y 2012, del Ministerio de Hacienda y Administraciones Públicas, para analizar el uso temporal de las construcciones, merced a la información sobre «Población máxima estacional».

Con todo ello, partimos de una caracterización social y territorial de la región, seguida de una valoración de las fases demográficas recientes en el contexto español. Comprobamos el grado de depresión y desestructuración existentes a comienzos del siglo XXI y cómo la crisis ha incidido en los incipientes cambios de tendencia surgidos en esos años, para revisar la situación económica, social y territorial actual, en la que se observa un flujo creciente hacia la ocupación del espacio rural por nuevos pobladores. Éstos pueden ser vistos como la semilla de un cambio más profundo, en el que se podrán corregir los caracteres más lacerantes del rural profundo de una de las regiones más extensas de Europa.

\section{LAS ETAPAS DEMOGRÁFICAS DEL ESPACIO RURAL DE CASTILLA Y LEÓN: DEL AUGE AL DECLIVE SOSTENIDO Y A LA RECUPERACIÓN PUNTUAL}

Habitualmente se olvida o se margina la fase de consolidación demográfica que tuvo lugar en la primera mitad de siglo XX en Castilla y León, al igual que en España, que se quiebra con 
la fase de éxodo rural, la cual, frente a lo sucedido en otras regiones, no produjo los mismos resultados que en ésta, por cuanto aquí el proceso de vaciamiento fue más intenso y duradero.

\section{De la fase de consolidación a la del declive y desestructuración demográfica}

Mediado el siglo XX, como es conocido, comienza en la región un cambio económico, social y territorial drástico, acorde con lo que estaba sucediendo en el resto de España, basado en el proceso de modernización, que obligó a abandonar el campo a millones de habitantes rurales. La concentración en tan pocos años de un éxodo rural impresionante acarreó indudables mejoras económicas y sociales, pero fue acompañado de claros desequilibrios territoriales.

Las mejoras económicas, derivadas de la industrialización, favorecieron a las regiones con materias primas, o con recursos y tradición industrial, o a las situadas en los ejes estratégicos de transporte o en las áreas costeras, lo que, a la postre, derivó en una polarización y desequilibrios territoriales, como consecuencia de la concentración de la actividad económica en unas regiones, frente a la despoblación en otras, básicamente rurales del interior peninsular, siendo éstas las más afectadas por el éxodo, ya que todas ellas perdieron población de forma significativa. Castilla y León, una región fundamentalmente agraria y rural, se quedó estancada y la despoblación se convirtió en su carácter esencial. Mientras España ganaba habitantes, Castilla y León los perdía, con un saldo de 385.260 personas menos en 2000 que en 1950. Si en este año contaba con 2.864 .378 h, en el 2000 caía a los 2.479 .118 , lo que supuso una pérdida del $13,45 \%$. Por el contrario, el territorio español pasó de 28.117 .873 h en 1950 , a 40.499 .791 en el año 2000, un incremento del 44\% (12.381.918 personas), resultado de la situación de bonanza por la que atravesó el país en términos generales (véase figura 1).

Figura 1

EVOLUCIÓN DE LA POBLACIÓN DE CASTILLA YLEÓN 1900-2011

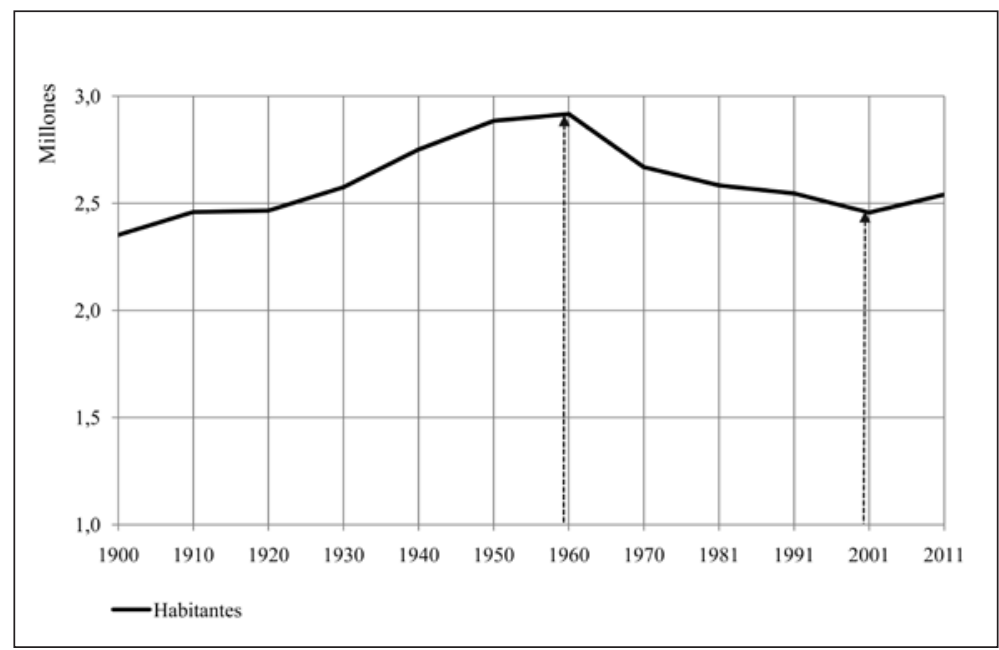

Fuente: INE, Censos de Población y Viviendas, 1900 a 2011 
Los años cincuenta y sesenta, como es bien conocido, representan el periodo de transición, donde el crecimiento económico y demográfico se generaliza, aunque con destacables diferencias territoriales, ya que el mayor crecimiento tuvo lugar en las regiones industriales, -Madrid, Cataluña o el País Vasco-, a las que se añade la franja litoral, casi en su totalidad, que comienza a incrementar su peso demográfico, como consecuencia del despliegue del turismo a partir del decenio del sesenta. Frente a los espacios que ganan población, el interior peninsular, salvo Madrid, la pierde. Es lo que sucede en Castilla y León. La figura 1 pone de manifiesto una pérdida constante de habitantes, desde 1955 -aunque el Censo de 1960 todavía no recoge las pérdidas que se producen desde mediado el decenio- hasta el comienzo del siglo XXI.

Esta caída se traduce en una polarización y desequilibrios territoriales. Son absolutamente predominantes los municipios que pierden población, ya que suman 2.109 de un total de 2.248. Por su parte, los que ganan son las capitales de provincia y algunas ciudades pequeñas, como Ponferrada, que crece en casi 39.000 personas, o Aranda de Duero, que lo hace en cerca de 20.000. Esta dinámica contrasta fuertemente con la de la etapa anterior, desde principios de siglo, en la que se había mantenido el crecimiento de una manera sostenida y clara.

Sin embargo, tras años de regresión demográfica, se está produciendo un movimiento en sentido contrario, que afecta a un escaso número de municipios, pero que no se puede despreciar. De hecho, uno de cada cinco municipios rurales de la región ha tenido un balance positivo de población en el siglo XXI. Interesa conocer esta nueva dinámica, sus causas y los caracteres de los territorios afectados. Por ello, debemos concretar, en primer lugar, el ámbito de estudio, por cuanto no podemos mezclar municipios rurales con otros periurbanos, que indudablemente están teniendo saldos positivos, pero que derivan de una dinámica urbana clara, por más que conserven su aspecto rural.

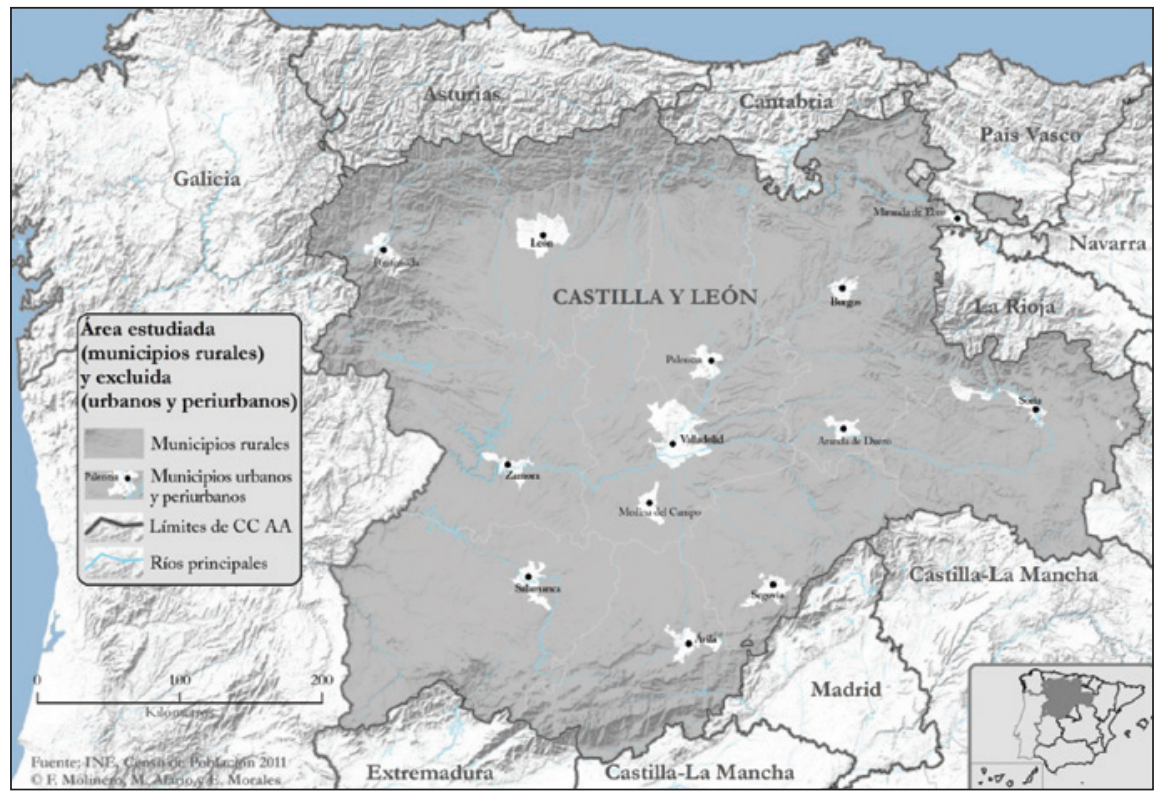


En la figura 2, hemos delimitado el ámbito de estudio, aplicando criterios cuantitativos y objetivos, por un lado, a los que hemos añadido criterios cualitativos, por otro. La definición que hace la Ley 45/2007 de Desarrollo Sostenible del Medio Rural, con sus modificaciones posteriores, nos permite conceptuar como rurales los municipios menores de $30.000 \mathrm{~h}$ que, al mismo tiempo, tengan una densidad inferior a $100 \mathrm{~h} / \mathrm{km}^{2}$. De este modo, evitamos el mero umbral cuantitativo de los 2.000, o de los $10.000 \mathrm{~h}$, que en los alrededores de las ciudades calificarían a numerosos municipios como rurales cuando se integran en una categoría de poblamiento periurbano, el cual difiere enormemente de la dinámica, los caracteres y la estructura de los municipios rurales. Hemos valorado, al mismo tiempo, el hecho de que algunos municipios «rurales» de los entornos periurbanos, tienen una dinámica periurbana, y no rural, por cuanto están creciendo a base de urbanizaciones, a pesar de que no llegan ni a los 30.000 h, ni a los umbrales de densidad contemplados en la Ley 45/2007. A éstos los hemos incluido entre los rurales unas veces, o excluido otras, basándonos en la dinámica demográfica, en el conocimiento directo y en la proliferación, o no, de urbanizaciones. Todo ello, nos ha permitido definir como rurales a 2.193 municipios de Castilla y León, sobre un total de 2.248, que aparecen recogidos en el mapa (figura 2), y represen$\tan$ el $18 \%$ del territorio español, aunque tan solo el 2,3\% de sus habitantes.

El problema no debe plantearse en términos de pérdida de habitantes exclusivamente, sino en la bajísima densidad, que queda por debajo de $8 \mathrm{~h} / \mathrm{km}^{2}$ en la mayor parte de los municipios rurales, con una media de 12 , y en todo lo que este proceso demográfico implica para el territorio: masculinización, envejecimiento, falta de servicios, abandono de actividades y elementos tradicionales, abundancia de jubilados y predominio absoluto de las actividades agrarias, como veremos, por más que a menudo se niegue este hecho. Estos aspectos, conocidos y estudiados, no deben encubrir la trascendencia que tienen y el papel que juegan en la desarticulación de la sociedad rural, por más que, contemplados con voluntarismo u oportunismo, se pretenda confundir la dinámica de este rural profundo con la de otra parte del rural regional que empieza a moverse.

\section{La marcha hacia una incierta recuperación}

En efecto, si la segunda mitad del s. XX destacó por los saldos negativos continuos, ya en el siglo actual parece producirse un cambio de tendencia, en gran medida relacionado con la bonanza económica general, que afecta incluso a algunos pueblos del rural profundo de Castilla y León, en los que se han asentado inmigrantes que trabajan fundamentalmente en actividades agrícolas, ganaderas y en algunos servicios de atención a las personas mayores y en el comercio, además de algunos otros profesionales. De hecho, al margen de la fiabilidad estadística, podemos comprobar que en el decenio 2001 a 2011 se produce un cambio de tendencia demográfica desconocido hasta entonces en los municipios rurales. Así, frente al periodo 1950-2000, en el que tan solo las ciudades, sus periurbanos y una veintena más de centros comarcales ganaban población, en el lapso transcurrido en el s. XXI ha habido un total de 423 municipios que han incrementado su población en 61.085 h, por más que el resto de los rurales (1.770, incluidos 19 con saldo neutro) hayan perdido 97.817 , dando un balance conjunto de pérdidas de un 3,3\% respecto a la población de principios de este siglo.

Si consideramos la región en conjunto, se produce una ganancia pequeña; si consideramos solo los municipios rurales, el saldo continúa siendo negativo, pero si analizamos la 
distribución de los que ganan y pierden, podemos observar unos fenómenos significativos, que en determinados casos pueden ser meramente azarosos, pero que, en otros, revelan una dinámica espacial singular, como se aprecia en el mapa de los saldos de población censal entre 2001 y 2011 a escala municipal.

Figura 3

BALANCE DE POBLACIÓN EN LOS MUNICIPIOS RURALES DE CASTILLA Y LEÓN ENTRE 2001 Y 2011

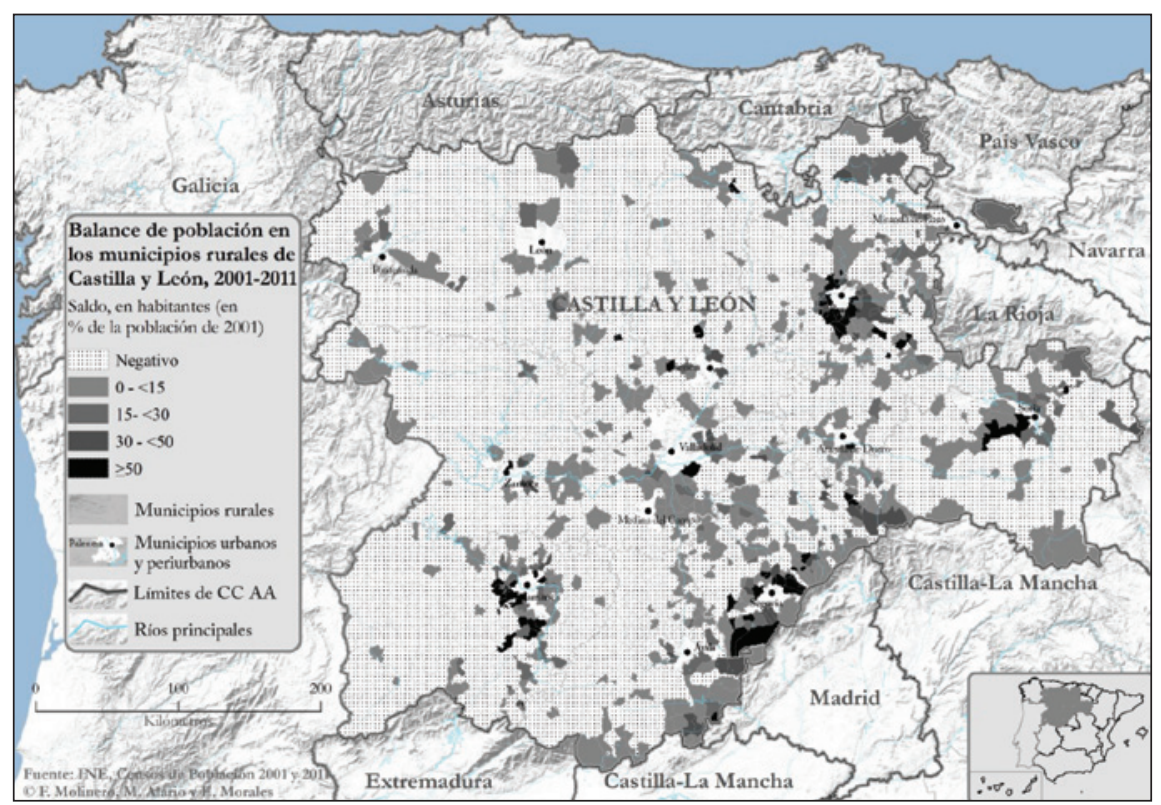

Así, la figura 3 muestra que los balances positivos de población se dan en determinadas comarcas y en los ejes más dinámicos. Llama en primer lugar, la atención el área de influencia de Madrid, que desde hace varios decenios está siendo ocupada por residencias secundarias, y a veces principales, pertenecientes fundamentalmente a madrileños. El sur y este de Ávila, una buena parte de la provincia de Segovia, el eje de la carretera Nacional-1, desde Madrid a San Sebastián, constituyen las franjas o áreas más dinámicas y claras, a las que se une el eje de la carretera N-620, entre Salamanca y Burgos, además del de la N-VI, y el de la N-601 de Valladolid a León, a los que se añaden algunas otras comarcas y sectores puntuales.

Pese al escaso aumento, se trata de una situación de crecimiento, que, aunque débil y lento, ha cambiado la tendencia negativa que mantuvo la región a lo largo del siglo XX. No es un cambio decisivo, ya que el crecimiento es prácticamente inapreciable $(3,4 \%$ para toda la región en una década); sin embargo, se trata de un balance positivo, situación que no se daba anteriormente. Castilla y León ha pasado de tener 2.456.474 h en 2001 a 2.540.188 en el 2011. Si lo comparamos con el conjunto español, que también ha mantenido un crecimiento positivo, podemos comprobar la enorme distancia que separa a ambos conjuntos. Mientras España ganó 12,6 Mh en la segunda mitad del siglo XX (45\%) y 6 Mh en el periodo 2001-2011 (14,6\%), Castilla y León perdió un $14,8 \%$ en la primera fase, mientras ganó un 3,4\% en la segunda. De manera que los primeros años del siglo XXI han supuesto un crecimiento positivo tanto para España como para Castilla y León, 
aunque la entidad de su crecimiento ha sido enormemente dispar, si bien la región, como un todo, ha invertido el signo regresivo de los largos decenios anteriores.

No obstante, la dinámica territorial no ha cambiado respecto a la fase anterior. Continúan existiendo importantes desequilibrios territoriales y vacíos demográficos. El crecimiento negativo sigue dominando, pues son 1.751 municipios rurales que han perdido población. No es un dato significativo si lo comparamos con el periodo anterior, en el que eran 2.127 los que perdían. Lo destacable es que una quinta parte de los municipios rurales regionales ha ganado población.

A este incremento no solo contribuye la significativa llegada de inmigrantes extranjeros, sino que también incide el retorno de quienes emigraron en el periodo de la industrialización, y junto a ellos, la llegada de nuevos pobladores, que han decidido asentarse en esta región movidos por la cercanía y la mejora de las infraestructuras, de modo que los movimientos pendulares cobran una relativa importancia, como sucede en el borde meridional de la Cordillera Central, donde reside mucha gente que trabaja en Madrid y vive en municipios de Ávila o Segovia.

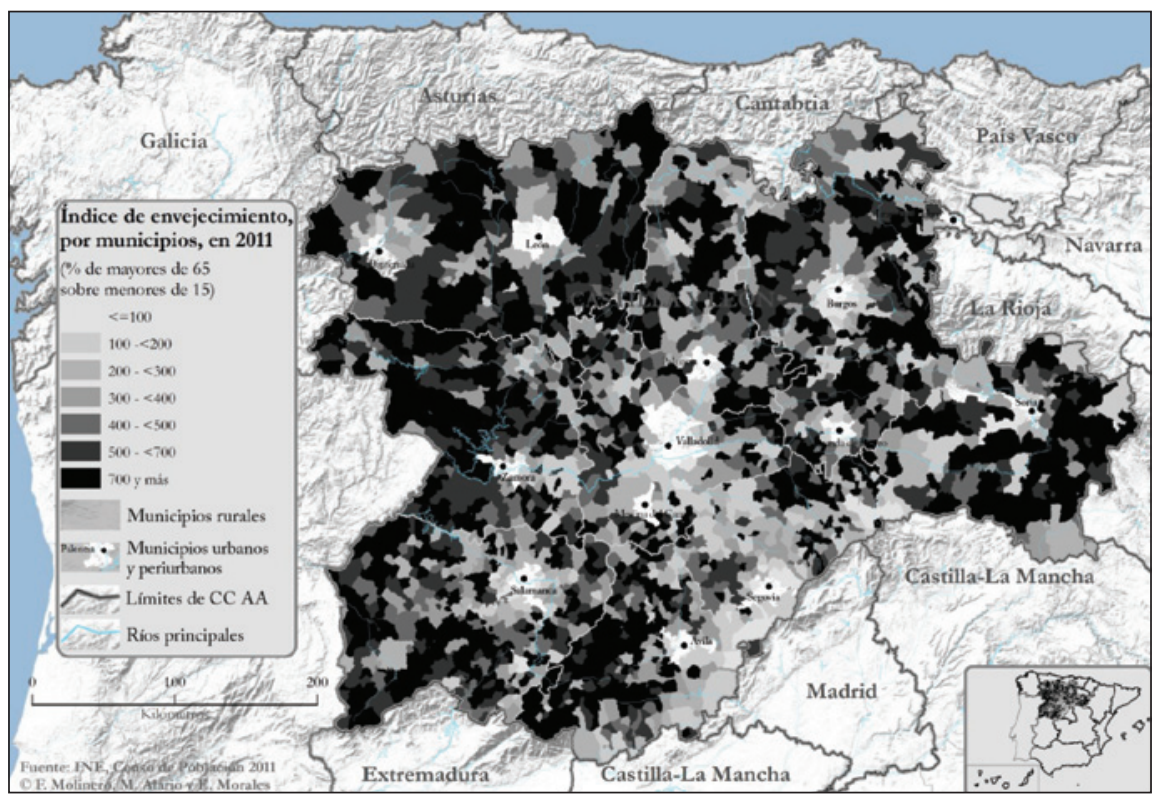

¿Pero se puede hablar de nuevos pobladores en un medio rural como el de Castilla y León? Se entiende por nuevo poblador la persona que realiza un movimiento migratorio desde el medio urbano al rural, y que, habiendo vivido en zonas urbanas, decide fijar su residencia, y en la medida de lo posible su actividad laboral, en el entorno rural, movida por la búsqueda de una mayor calidad de vida y ambiental, nuevas oportunidades de empleo, un modelo de vivienda diferente al de las ciudades, generando desde el punto de vista urbanístico nuevos asentamien- 
tos o modificando los existentes (Morales y Alario, 2012: 215). La llegada de nuevos pobladores se interpreta como una superación de la atonía, aunque no compensa las salidas de otros y mucho menos las pérdidas debidas al saldo vegetativo. Desde el punto de vista espacial, esta llegada de población ha repercutido positivamente en casos puntuales, allí donde ha compensado el crecimiento vegetativo negativo. De este modo, aunque la llegada de nuevos pobladores, -extranjeros (a menudo procedentes del medio rural de su país) o nacionales-, ha supuesto un cambio incipiente, no ha sido capaz de corregir los desequilibrios y los indicadores demográficos negativos, entre los que destaca el elevado índice de envejecimiento (figura 4), que, en cierto modo, si lo comparamos con los municipios que crecen (figura 3), parece un negativo.

No puede sorprender esta situación, porque el envejecimiento se acompaña de una falta evidente de nacimientos, aunque sí sorprenden los elevadísimos índices, dado que hay más de un $60 \%$ de los municipios rurales $(=1.324)$ que superan el índice 500, es decir, que hay más de 5 mayores de 65 por cada menor de 15 años, que se distribuyen por más de 50.000 $\mathrm{km}^{2}$. De hecho, los jubilados y ancianos representan una parte sustancial de la población de este medio rural envejecido (28,4\%), en el que se alcanza un índice de vejez medio de 290,6, frente a la media de España de 107, o de la Comunidad Autónoma, de 177. Si nos atenemos a lo que indican los datos del siglo XXI estaríamos cambiando el signo de la regresión y de los valores negativos, al menos en ese grupo de municipios localizados cerca de Madrid, de las capitales regionales o de los ejes más dinámicos de Castilla y León. Pero no está claro que esa tendencia se mantenga hacia el futuro, o que incluso se haya detenido ya con la crisis. Así parecen indicarlo los últimos datos del padrón continuo de población, pues si lo aplicamos a los últimos tres años (2011 a 2013), tendríamos una pérdida de casi 33.000 habitantes en los municipios rurales, y los 423 que habían ganado hasta 2011, se reducían a 310 en los últimos tres años, lo que demuestra que no se ha consolidado la tendencia.

Frente a ello, lo que sí resiste es el poblamiento. La población declina y hasta se hunde, pero los pueblos, las entidades de población se mantienen.

\section{EL MANTENIMIENTO DE LA RED DE POBLAMIENTO Y SU CRECIMIENTO EN EDIFICIOS Y VIVIENDAS}

Frente a la dinámica generalizadamente regresiva de la población regional, la del poblamiento es, por el contrario, estable e, incluso, positiva. Entre el año 2000 y 2013 el número de municipios tan solo se ha visto incrementado en uno, de 2.247 a 2248. Se trata del caso de San Cristóbal de Segovia, que se reconoce como municipio en el año 2001, tras segregarse del de Palazuelos de Eresma, apoyado en un destacable crecimiento demográfico derivado de su condición de espacio periurbano de la capital segoviana.

El número de municipios no es, sin embargo, significativo para analizar un poblamiento complejo, en el que predominan municipios con varias unidades poblacionales, tanto núcleos como diseminados, cuya valoración es sólo posible a través de los datos del nomenclátor de población. Según el Instituto Nacional de Estadística, en 2013 había en Castilla y León un total de 8.315 unidades poblacionales, de las que poco más de una cuarta parte correspondía a diseminados y el resto, 5.911, a núcleos de población con personalidad espacial diferenciada, según definición del propio INE. Estos datos suponen un ligero incremento con respecto a los del año 2000, ya que este nomenclátor registraba 8.157 unidades de población, de las que 5.854 eran núcleos. 
Mientras que la población regional crece ligeramente y la rural retrocede, el número de unidades poblacionales aumenta, circunstancia derivada, en parte, del registro como «núcleos» de urbanizaciones de segunda residencia, algunas localizadas en espacios periurbanos, aunque pocas en los rurales, que mantienen estable su red de poblamiento. Una densa trama que sirve a una escasa y polarizada población, lo que se traduce en unidades de tamaño mínimo, dispersas por todo el espacio regional, con lo que ello conlleva de dificultades de articulación territorial, acceso a los servicios y mantenimiento de infraestructuras mínimas de atención a las necesidades de los habitantes, especialmente difíciles en el caso de las unidades de poblamiento rural.

Cuadro 1

POBLAMIENTO DE CASTILLA Y LEÓN EN 2013 Y 2000, POR PROVINCIAS

\begin{tabular}{|c|c|c|c|c|c|c|c|}
\hline \multicolumn{8}{|c|}{ Año 2013} \\
\hline & \multicolumn{2}{|c|}{ Núcleos } & \multicolumn{2}{|c|}{ Diseminados } & \multicolumn{3}{|c|}{ Total } \\
\hline Provincia & $\mathrm{N}^{\mathrm{o}}$ & Habitantes & $\mathrm{N}^{\mathrm{o}}$ U.P. & Habitantes & $\mathrm{N}^{\mathrm{o}}$ U.P. & Habitantes & $\mathrm{N}^{\mathrm{o}}$ municipios \\
\hline Ávila & 452 & 167.554 & 156 & 1.271 & 608 & 168.825 & 248 \\
\hline Burgos & 1.273 & 369.597 & 256 & 1.651 & 1.529 & 371.248 & 371 \\
\hline León & 1.411 & 486.778 & 355 & 2.974 & 1.766 & 489.752 & 210 \\
\hline Palencia & 471 & 164.657 & 189 & 4.298 & 660 & 168.955 & 191 \\
\hline Salamanca & 560 & 341.095 & 715 & 4.453 & 1.275 & 345.548 & 362 \\
\hline Segovia & 389 & 160.715 & 269 & 987 & 658 & 161.702 & 209 \\
\hline Soria & 506 & 93.288 & 59 & 3 & 565 & 93.291 & 183 \\
\hline Valladolid & 329 & 528.873 & 133 & 3.411 & 462 & 532.284 & 226 \\
\hline Zamora & 520 & 185.249 & 272 & 3.021 & 792 & 188.270 & 248 \\
\hline Total CyL & 5.911 & 2.497 .806 & 2.404 & 22.069 & 8.315 & 2.519 .875 & 2.248 \\
\hline \multicolumn{8}{|c|}{ Año 2000} \\
\hline Provincia & $\mathrm{N}^{\mathrm{o}}$ & Habitantes & No U.P. & Habitantes & $\mathrm{N}^{\mathrm{o}}$ U.P. & Habitantes & $\mathrm{N}^{\mathrm{o}}$ municipios \\
\hline Ávila & 450 & 164.079 & 152 & 912 & 602 & 164.991 & 248 \\
\hline Burgos & 1.261 & 345.731 & 250 & 1.509 & 1.511 & 347.240 & 371 \\
\hline León & 1.409 & 499.385 & 325 & 2.770 & 1.734 & 502.155 & 210 \\
\hline Palencia & 468 & 174.656 & 185 & 3.660 & 653 & 178.316 & 191 \\
\hline Salamanca* & 549 & 343.218 & 700 & 5.226 & 1.249 & 348.444 & 362 \\
\hline Segovia** & 381 & 145.668 & 247 & 613 & 628 & 146.281 & 208 \\
\hline Soria & 505 & 90.900 & 58 & 11 & 563 & 90.911 & 183 \\
\hline Valladolid & 311 & 492.158 & 130 & 3.532 & 441 & 495.690 & 226 \\
\hline Zamora & 520 & 200.504 & 256 & 2.965 & 776 & 203.469 & 248 \\
\hline Total general & 5.854 & 2.456 .299 & 2.303 & 21.198 & 8.157 & 2.477 .497 & 2.247 \\
\hline
\end{tabular}

Fuente: INE, Nomenclátores de 2013 y 2000. Elaboración propia.

* Hay 1.289 h no registrados, al no existir datos desagregados por unidades poblacionales. Deben sumarse a la población total provincial para obtener la población oficial de la provincia. ** Hay 332 h que no aparecen registrados. Ídem que para Salamanca. 
Cuadro 2

ESTRUCTURA DE LAS UNIDADES POBLACIONALES DE CASTILLA Y LEÓN EN 2013, POR TAMAÑO DEMOGRÁFICO

\begin{tabular}{|c|c|c|c|c|}
\hline \multirow[b]{2}{*}{ Tamaño en habitantes } & \multicolumn{2}{|c|}{ Núcleos } & \multicolumn{2}{|c|}{ Diseminados } \\
\hline & $\%$ de U.P. & $\%$ de habitantes & $\%$ de U.P. & $\%$ de habitantes \\
\hline 0 & 1,56 & - & 40,31 & - \\
\hline De 1 a 9 & 9,96 & 0,13 & 42,39 & 17,91 \\
\hline De 10 a 49 & 36,39 & 2,28 & 14,56 & 30,44 \\
\hline De 50 a 99 & 17,86 & 3,01 & 1,71 & 13,04 \\
\hline De 100 a 199 & 14,84 & 4,96 & 0,58 & 9,18 \\
\hline De 200 a 499 & 11,66 & 8,44 & 0,29 & 8,91 \\
\hline De 500 a 999 & 3,77 & 6,28 & 0,12 & 9,65 \\
\hline De 1.000 a 1.999 & 1,98 & 6,58 & - & - \\
\hline De 2.000 a 4.999 & 1,13 & 8,40 & 0,04 & 10,87 \\
\hline De 5.000 a 9.999 & 0,47 & 7,47 & - & - \\
\hline$>=10.000$ & 0,37 & 52,45 & - & - \\
\hline
\end{tabular}

Fuente: INE, Nomenclátor 2000 y 2013. Elaboración propia.

Por lo que se refiere a los diseminados, en una región de poblamiento fundamentalmente concentrado, como Castilla y León, no constituyen elementos de importancia ni cuantitativa ni cualitativa, pues, con un $28 \%$ de las unidades poblacionales, albergan a menos del $1 \%$ de la población. Los diseminados, localizados especialmente en la provincia de Salamanca, seguida de León, Zamora, Segovia y Burgos, son, en su gran mayoría, granjas, caseríos, dehesas, estaciones y otros elementos singulares, en buena parte de los casos sin ningún habitante registrado, ya que tienen un uso principalmente temporal o nulo. Así, en el nomenclátor del 2.000, un $41 \%$ de los casos carece de habitantes registrados y el $80 \%$ no alcanza los 10 habitantes, dato que en 2013 se eleva al $82 \%$ de los diseminados. En este año tan solo 25 superan los 100 habitantes, y corresponden a los entornos urbanos de Palencia, Ponferrada, Aranda, Laguna de Duero u otras ciudades (véanse cuadros 1 y 2). 
La red de núcleos es la fundamental en número (71\% de U.P. y $99 \%$ de la población) y constituye la estructura básica del poblamiento regional. Son claramente dominantes los núcleos de muy pequeño tamaño, con más del $21 \%$ por debajo de 10 habitantes y más del $90 \%$ por debajo de 500 personas registradas. De hecho, solo 22 núcleos pueden considerarse, según los criterios estadísticos del INE, estrictamente urbanos, al superar los 10.000 habitantes y se corresponden con las capitales provinciales, más las ciudades no capitales de importancia industrial como Ponferrada, Aranda de Duero, Miranda de Ebro, destacables centros comarcales de servicios como La Bañeza, Astorga, Benavente, Medina del Campo, Béjar o Ciudad Rodrigo, que cuentan también con industrias tradicionales, y algunos núcleos periurbanos como Laguna de Duero, Arroyo de la Encomienda, Trobajo del Camino o Santa Marta de Tormes, si bien la delimitación realizada para este estudio incluye otra treintena de municipios periurbanos dinámicos.

El grueso de la red de unidades poblacionales, tanto en núcleo como en diseminado, se corresponde, sin duda, con el poblamiento rural, justamente el espacio que presenta unos balances demográficos mayoritariamente negativos, que, sin embargo, no ve desaparecer ninguno de sus elementos poblacionales, los cuales, incluso, se incrementan en los últimos años, gracias a la consolidación y reconocimiento oficial de nuevas unidades, básicamente urbanizaciones. Proceso este que responde a la emergencia de lo que se ha dado en llamar «el uso temporal del territorio», que no es más que el desarrollo de funciones residenciales temporales, vinculadas a la función turística de los espacios rurales, tanto en su vertiente de residencia secundaria como de despegue de los nuevos alojamientos de turismo rural, regulados por la normativa regional.

\section{LOS USOS RESIDENCIALES TEMPORALES: ¿SALVACIÓN DE LOS ESPACIOS RURALES DE CASTILLA Y LEÓN?}

La tradición del ocio rural de los «hijos del pueblo» justifica el retorno temporal de los emigrantes del éxodo masivo de los años 60. Constituyen el principal soporte para el mantenimiento del caserío o incluso para nuevas viviendas. Sin embargo, a esta corriente, que es muy estacional o temporal, se suma la de los nuevos turistas rurales, movidos por la mentalidad clorófila y por la tranquilidad del ambiente rural, en el que se ofrecen servicios turísticos para cubrir la demanda urbana. Se añade a ambos movimientos el de los profesionales, también atraídos por la ideología clorófila, que aportan una nueva nota de diversidad. No obstante, el crecimiento consolidado de algunos municipios rurales se debe fundamentalmente a los habitantes que residen en los entornos periurbanos laxos y en algunas comarcas y ejes dinámicos. Es en esos segmentos territoriales privilegiados del espacio rural donde se empadronan y se asientan como opción de vida. La entidad y significado de cada grupo es muy diferente.

\section{El valor de la población estacional o flotante}

De entrada, es llamativo el hecho de que la población flotante total de los municipios rurales, tal como viene definida en la Encuesta de Infraestructuras, alcance una 
Figura 5

POBLACIÓN MÁXIMA ESTACIONAL SOBRE POBLACIÓN EMPADRONADA. MUNICIPIOS NO URBANOS DE CASTILLA Y LEÓN, 2011

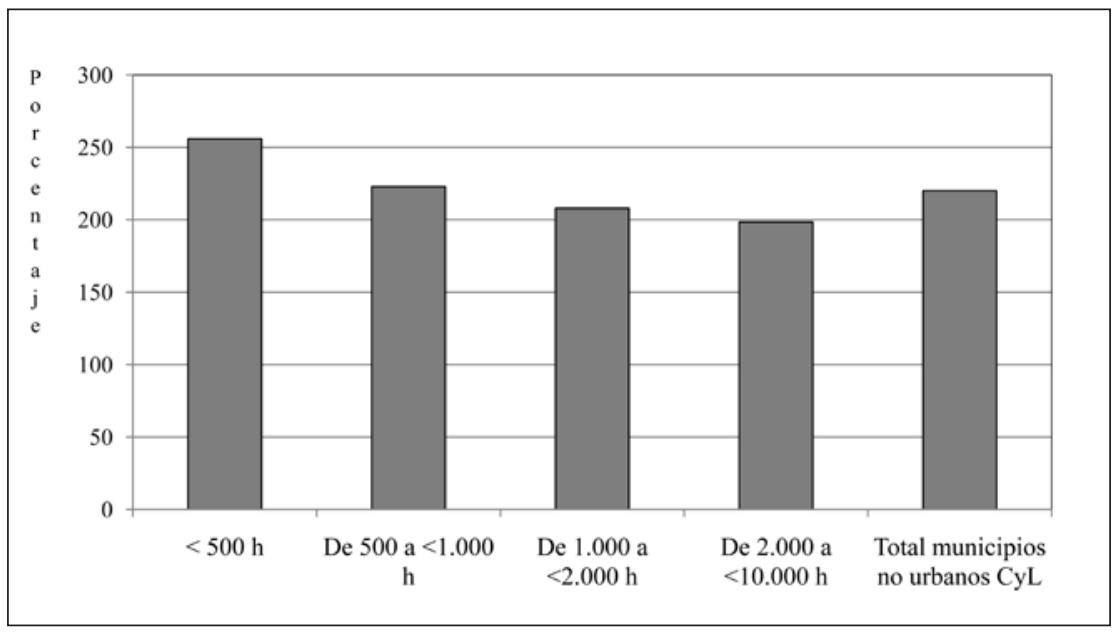

Fuente: INE: Encuesta de Infraestructuras 2011 para los núcleos principales de municipios menores de 10.000 h. Castilla y León 2011.

Figura 6

DISTRIBUCIÓN MUNICIPAL DE LA POBLACIÓN MÁXIMA ESTACIONAL, EN LAS ÁREAS RURALES DE CASTILLA Y LEÓN EN 2011

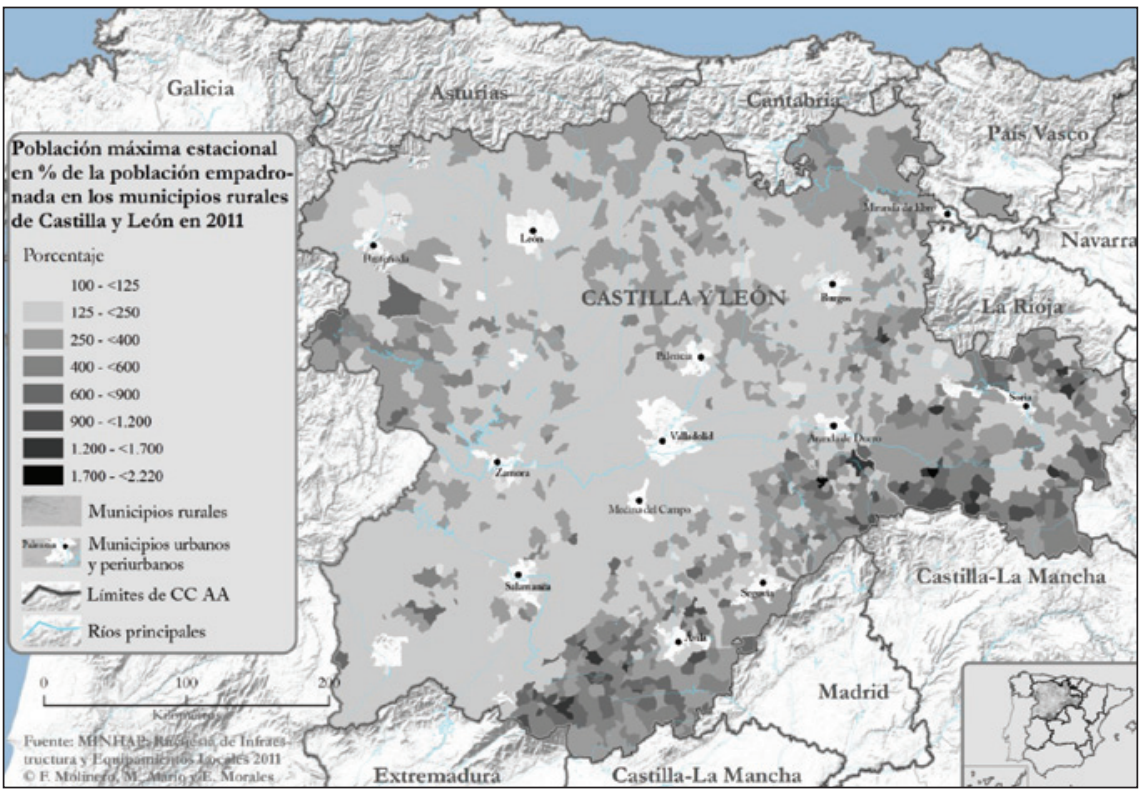


media de $221 \%$, es decir, que los habitantes de los meses de julio y agosto más otros periodos vacacionales multiplican por 2,2 el número de habitantes residentes. Pero esa media esconde un fenómeno más llamativo, y hasta espectacular: el incremento poblacional de los pueblos más atractivos llega a multiplicar por 10 y hasta por 22 el número de pobladores habituales. Basta con echar un vistazo a la figura 5 para comprobar que son los municipios más pequeños los que más incrementan su población residente, aunque este hecho no permite ver la distribución de los residentes temporales, que, en gran medida coincide con los espacios de fuerza señalados, porque la figura 6 muestra claramente la localización y situación de las áreas más atractivas, en nítida sintonía con el resto de variables.

Podemos observar, en consecuencia, un movimiento de especialización en viviendas secundarias, que, en los pueblos más dinámicos, se han convertido en principales, como sucede en las franjas externas del área de influencia de Madrid, que desborda la vertiente meridional de la Cordillera Central y salta a la septentrional en las provincias de Ávila, Segovia y Soria, afectando incluso a sus piedemontes y llanuras. Es evidente, pero también lo es en el NO de Zamora y en una buena porción del N de Palencia y de Burgos y del NE de León. Generalmente, se trata de residentes estacionales, que aportan temporalmente recursos y dinamismo a los pueblos. Sin embargo, es curioso comprobar que los máximos estacionales coinciden en una gran parte con los municipios que crecen (confróntese este mapa con el de la figura 3). Esta coincidencia espacial se debe en buena medida a la fuerza de la expansión urbana, pero también a la valoración del medio rural, especialmente el de aquellos municipios que son más accesibles y con buenos servicios, por un lado, y a los que, teniendo escasa accesibilidad, como los de la montaña soriana o los de la alta montaña de Palencia y León, o los de Sanabria en Zamora, cuentan con un atractivo especial, por otro.

La consecuencia de este atractivo es la proliferación de urbanizaciones en unos casos, o la reconstrucción, recuperación o levantamiento ex novo de casas -más que viviendas, ya que no se construyen para «vivir» en ellas, sino para pasar el tiempo de ocio-, en otros, con el matiz de que las más próximas a Madrid y a las capitales de provincia se convierten a menudo en residencias principales y sus habitantes en nuevos pobladores rurales, aunque alejados de las franjas periurbanas próximas a las ciudades.

\section{La entidad y significado de las nuevas construcciones}

El crecimiento de las segundas residencias en los espacios de desbordamiento de las áreas urbanas y en las de atractivo rural es un hecho incuestionable, como lo confirma el estudio de los Censos de Población y Viviendas. Basta observar la figura 7 para comprobar que son los municipios de entre 2.000 y $20.000 \mathrm{~h}$-la mayoría rurales- los que tienen más alto grado de renovación del caserío, en el que, además, predominan las casas vacías, al contrario de lo que sucede en los municipios más pequeños. En todos ellos, la tasa de renovación o construcción de nuevas viviendas entre 2002 y 2011 fue muy elevada, por encima del $20 \%$ en la mayor parte de los casos, llegando a superar el $40 \%$ en los más grandes (figura 7), que son los que mejores perspectivas y servicios ofrecen 
a la población flotante. En estos el peso de las casas vacías recientemente construidas acapara los dos quintos del total de casas vacías.

Figura 7

CASAS CONSTRUIDAS ENTRE 2002 Y 2011, POR TAMAÑO DE MUNICIPIO

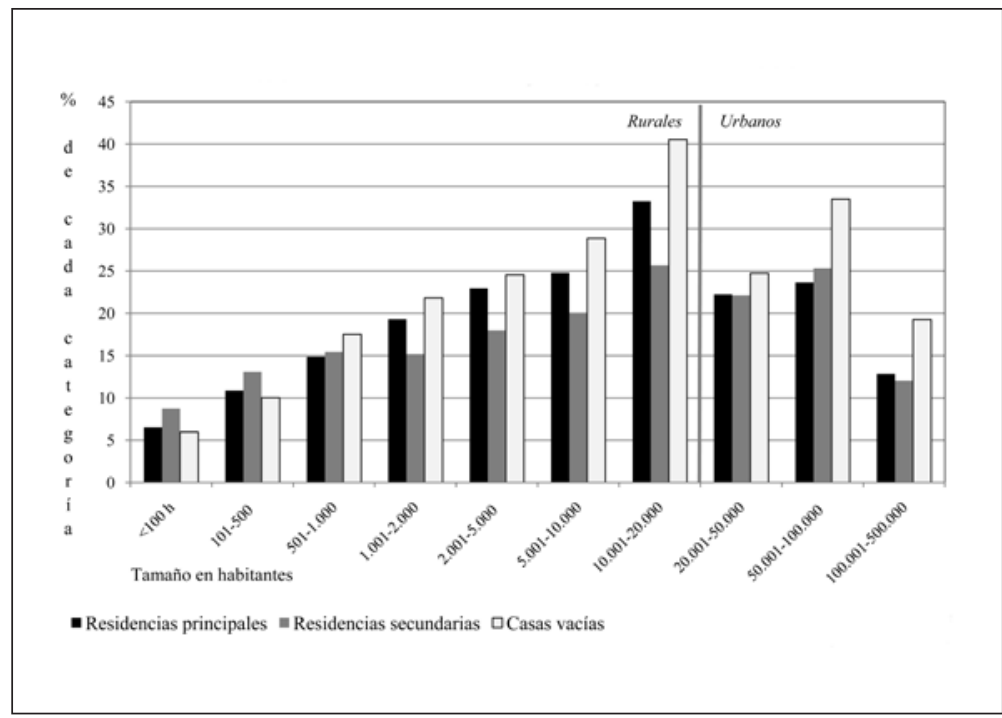

Fuente: INE, Censo de Población y Viviendas 2011

Las formas, localización y características de estas viviendas (tipo, edad, equipamiento...) tienen claros efectos en la organización de los núcleos, entre los que destaca la creación de nuevos barrios en las periferias y el abandono de los sectores centrales. Llaman asimismo la atención los contrastes morfológicos entre promociones, muchas de ellas con aspecto nítidamente urbano y abandono del tradicional. Hay algunas excepciones que basan su promoción en la recuperación de lo antiguo, al estilo de los pueblos rojos y negros de Segovia-Soria-Guadalajara, o en la Sierra de Candelario-La Alberca (Salamanca), en Covarrubias (Burgos), o en algunas comarcas de montaña...

Esta renovación afecta a un total de 183.495 casas construidas con posterioridad a 2002, lo que representa un $18 \%$ del total de casas de los municipios menores de $20.000 \mathrm{~h}$, las cuales superan el millón (cuadro 3). Se trata de un dinamismo considerable, por cuanto el espacio rural de España y, en concreto, el de Castilla y León, ha realizado un gran esfuerzo inversor en la renovación de sus viviendas y, como veremos más adelante, ha tenido, y tiene, una mayor proporción de ocupados en esta actividad económica que el medio urbano, por más que muchas casas estén vacías.

No obstante, a pesar del uso temporal de estas casas, como corresponde a la condición de no residentes de sus titulares, cada vez está teniendo más importancia otro tipo de construcciones rurales, que ayudan a renovar y mejorar el parque de viviendas: las casas rurales, a las que se suman otros alojamientos turísticos. 
Cuadro 3

VIVIENDAS PRINCIPALES, SECUNDARIAS Y CASAS VACÍAS SEGÚNAÑO DE CONSTRUCCIÓN Y TAMAÑO DE MUNICIPIO. CASTILLA Y LEÓN 2011

\begin{tabular}{|c|c|c|c|c|c|c|c|c|c|c|c|c|}
\hline & $\begin{array}{l}\text { Año de } \\
\text { construcción } \\
\text { y tamaño de } \\
\text { municipio }\end{array}$ & $<100 \mathrm{~h}$ & $101-500$ & $\begin{array}{r}501- \\
1.000 \\
\end{array}$ & $\begin{array}{r}1.001- \\
2.000\end{array}$ & $\begin{array}{r}2.001- \\
5.000 \\
\end{array}$ & $\begin{array}{c}5.001- \\
10.000\end{array}$ & $\begin{array}{r}10.001- \\
20.000 \\
\end{array}$ & $\begin{array}{r}\text { Total } \\
<20.000 \\
\end{array}$ & $\begin{array}{r}20.001- \\
50.000 \\
\end{array}$ & $\begin{array}{c}50.001- \\
100.000\end{array}$ & $\begin{array}{c}100.001- \\
500.000\end{array}$ \\
\hline \multirow{5}{*}{ 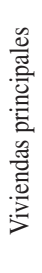 } & & 17.030 & 116.760 & 74.115 & 74.250 & 87.760 & 88.860 & 49.820 & 508.595 & 74.750 & 132.320 & 322.305 \\
\hline & $\begin{array}{l}\text { Antes de } \\
1900\end{array}$ & 3.830 & 16.645 & 6.585 & 5.285 & 3.780 & 1.820 & 710 & 38.655 & 575 & 805 & 2.440 \\
\hline & $1900-1950$ & 4.225 & 24.585 & 13.185 & 10.635 & 8.380 & 4.705 & 2.730 & 68.445 & 2.970 & 5.815 & 13.025 \\
\hline & $1951-2001$ & 7.070 & 60.110 & 41.400 & 42.200 & 52.935 & 58.110 & 28.635 & 290.460 & 52.955 & 89.825 & 250.455 \\
\hline & 2002-2011 & 1.110 & 12.670 & 11.020 & 14.340 & 20.145 & 22.015 & 16.555 & 97.855 & 16.610 & 31.295 & 41.360 \\
\hline \multirow{5}{*}{ 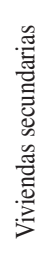 } & Total & 27.620 & 125.575 & 66.055 & 45.515 & 45.905 & 33.910 & 10.300 & 354.880 & 9.880 & 19.635 & 37.950 \\
\hline & $\begin{array}{l}\text { Antes de } \\
1900\end{array}$ & 5.145 & 16.295 & 5.880 & 5.275 & 2.925 & 560 & 400 & 36.480 & 290 & 345 & 485 \\
\hline & $1900-1950$ & 7.170 & 27.890 & 12.365 & 8.430 & 5.790 & 2.200 & 1.095 & 64.940 & 400 & 1.670 & 1.665 \\
\hline & $1951-2001$ & 11.790 & 62.525 & 36.635 & 24.360 & 27.980 & 23.985 & 6.060 & 193.335 & 6.960 & 12.400 & 30.710 \\
\hline & $2002-2011$ & 2.415 & 16.420 & 10.195 & 6.905 & 8.250 & 6.750 & 2.645 & 53.580 & 2.185 & 4.970 & 4.570 \\
\hline \multirow{5}{*}{ 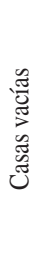 } & Total & 5.945 & 33.125 & 19.600 & 20.610 & 27.145 & 25.305 & 16.020 & 147.750 & 16.820 & 32.710 & 61.165 \\
\hline & $\begin{array}{l}\text { Antes de } \\
1900\end{array}$ & 2.040 & 7.655 & 3.115 & 2.600 & 2.310 & 1.280 & 475 & 19.475 & 295 & 510 & 1.415 \\
\hline & $1900-1950$ & 1.910 & 10.520 & 5.770 & 5.050 & 5.020 & 3.180 & 1.680 & 33.130 & 1.825 & 3.415 & 5.740 \\
\hline & $1951-2001$ & 1.540 & 11.275 & 7.170 & 8.195 & 13.015 & 13.265 & 7.290 & 61.750 & 10.300 & 17.525 & 41.060 \\
\hline & $2002-2011$ & 355 & 3.325 & 3.430 & 4.495 & 6.660 & 7.300 & 6.495 & 32.060 & 4.160 & 10.950 & 11.785 \\
\hline
\end{tabular}

N.B.: Los totales no coinciden con la suma de los parciales, por cuanto falta un pequeño número de viviendas en las que no consta el año de construcción. Fuente: INE Censo de Población y Viviendas 2011.

\section{El impulso renovador de las casas rurales y de otros alojamientos de turismo rural}

Castilla y León, gracias a su vastedad territorial, es la comunidad autónoma con mayor número de casas rurales de España, aunque no así con la mayor densidad. Sin embargo, la recuperación de antiguas viviendas o la construcción de otras nuevas pueden ser vistas como una moda cuyo auge se relacionaría con las ayudas derivadas de las políticas de desarrollo rural aplicadas desde los años 90 del siglo pasado, por lo que afecta a numerosísimos pueblos, con una concentración especial en los de mayor atractivo ambiental o cultural. Además, este tipo de casas suele edificarse con un estilo arquitectónico más respetuoso con las formas tradicionales que las viviendas normales; suelen utilizar los materiales de 
construcción de cada comarca (piedra caliza, granito, guijarro, adobe, tapial, o ladrillo), acompañados, por lo general, de vigas o entramados de madera, que se rematan con tejados nobles, de teja o pizarra. A menudo se han levantado con el marchamo de «casas rurales» algunas viviendas destinadas al uso exclusivo de sus propietarios, quienes se han visto en la obligación de ofrecerlas en alquiler durante unos cuantos años, pero, generalmente, se construyen con fines de arrendamiento o como alojamientos que incluyen servicios de restauración. Constituyen un elemento novedoso, en aumento, y que contribuye, aunque sea mínimamente, a la diversificación de funciones.

Tal como se aprecia en la figura 8, las plazas de turismo rural disponibles en la región se encuentran fundamentalmente en los municipios más pequeños, pues el cliente busca una tranquilidad que espera encontrar más fácilmente en ese tipo de pueblos. Así, para un total de 61.560 plazas de alojamiento de turismo rural, el 69\% se encuentra en los menores de $2.000 \mathrm{~h}$, aunque las plazas hoteleras tienden a concentrarse más en los municipios más grandes, sobre todo en los de más de 2.000 h, que acaparan casi la mitad de ese tipo de plazas en menos de un centenar de municipios.

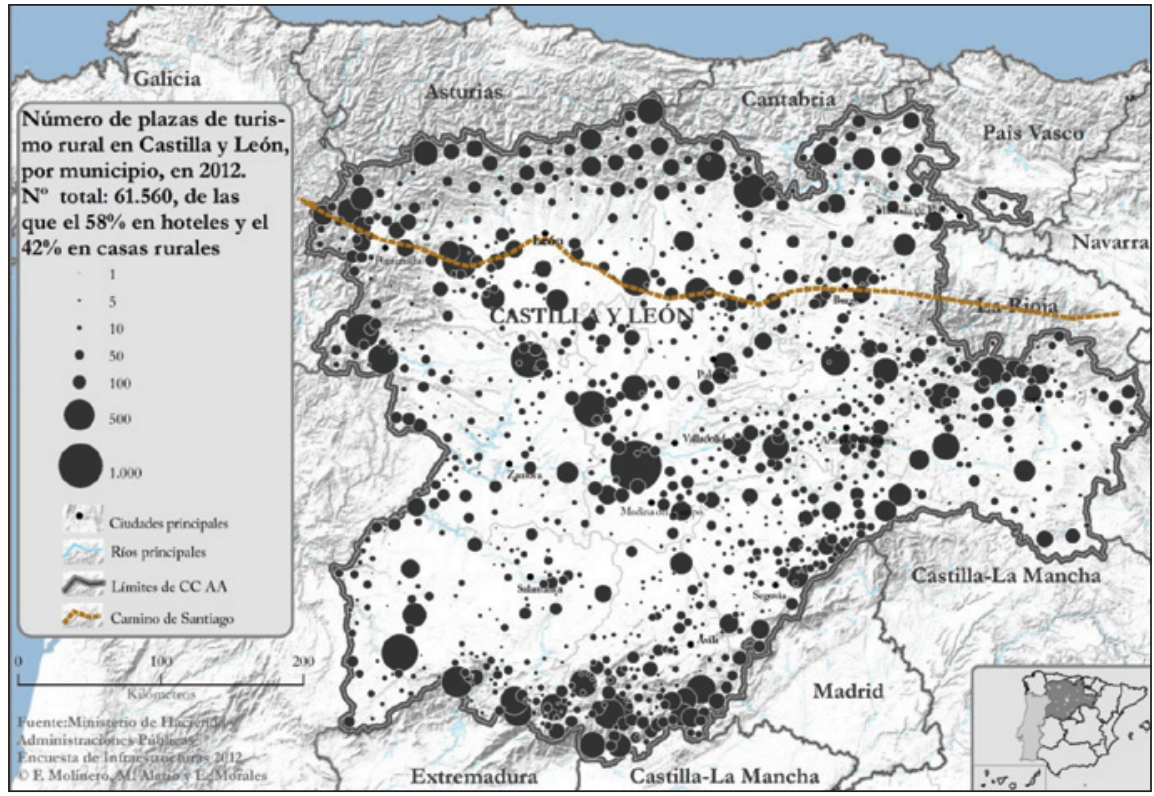

La distribución observable en la figura 8 confirma la tendencia a una cierta densificación en las comarcas rurales de mayor atractivo, especialmente cuando estas se encuentran próximas a grandes centros urbanos, que son los emisores de «turistas», es decir, de los potenciales clientes. De nuevo, son las vertientes meridionales de las sierras de Ávila y Segovia, secundadas por las de Salamanca y Soria, las que mayor densidad tienen, pero la Cordillera 
Cantábrica -en concreto la Montaña Oriental de León, la Montaña Palentina o las Merindades de Burgos-, en relación con Asturias y Bilbao, también muestra su valor. A todo ello se suma una dispersión general, correspondiente a una valoración creciente del campo, pero se nota, además, de una manera evidente, la importancia que está adquiriendo el Camino de Santiago en la oferta de alojamiento rural.

Todos estos aspectos tienen una nítida proyección y consecuencias en el empleo rural y en las actividades económicas. Está muy claro que esta región, de baja densidad y de abundancia de jubilados, es una región rural, en la que el empleo agrario ha caído a límites muy bajos, pero eso no es lo que ha sucedido en el campo, pues allí la diversificación económica se ha producido más por una merma de los ocupados agrarios que por un crecimiento del resto de los ocupados. El peso del empleo agrario es abrumador sobre una gran parte del territorio, a pesar de que los nuevos profesionales, que se distribuyen por los lugares más insospechados, estén modificando levemente el panorama dominante.

\section{El significado de los nuevos profesionales}

La contracción del mercado laboral en el ámbito rural de Castilla y León ha sido tan fuerte que cualquier leve movimiento incide en una nueva configuración. De este modo, la composición de los casi 264.000 ocupados rurales puede verse modificada por el añadido de unos pocos miles de empleos, como sucede durante los periodos estivales, especialmente en la rama de la restauración y del turismo rural. Las 3.872 casas rurales y centros de turismo rural (en 2012), aunque muchas son de alquiler sin ningún tipo de servicio, incrementan el empleo. Lo mismo podemos decir de otras actividades, especialmente de la construcción, que se orienta precisamente hacia la construcción de casas rurales y, sobre todo, a la renovación del parque general de viviendas, y que supone una de las ramas de empleo más destacables de la región.

No obstante, lo que más llama la atención en el segmento de los nuevos profesionales es la llegada de nuevos pobladores, muy poco numerosos, pero que tienden a crecer y que no se encasillan en una única actividad, como puede ser la del turismo rural, sino que optan por una diversificación profesional, en muchos casos manteniendo la actividad que desarrollaban en la ciudad, o bien iniciando otra nueva, de emprendimiento. Es el caso de una pareja de profesionales de Gamones (Zamora), que se trasladan al campo en busca de un estilo de vida distinto. Son un matrimonio asentado en un pueblo del Sayago, al que llegaron hace unos años. Él desarrolla su trabajo de diseñador gráfico telemáticamente; ella es ceramista, profesión que cuenta con gran tradición en el Sayago, como lo demuestran los «cacharros» que se elaboran en Pereruela. Este matrimonio es un ejemplo de cómo se puede cambiar la vida de la ciudad y adaptarse a la del pueblo sin mayor dificultad; sus hijos de 14 y 16 años también se han adaptado, desarrollando las actividades que cualquier joven de esta edad puede realizar en la ciudad, pero en el medio rural.

En la provincia de Palencia, encontramos varios ejemplos de nuevos pobladores, uno de ellos en Población de Arroyo, una pareja, él de nacionalidad española, y ella venezolana, que, junto a sus hijos, dieron el paso de irse a vivir al campo, romper con su vida anterior para dedicarse a la recogida de hierbas silvestres y la preparación de materias primas herba- 
les para la medicina alternativa, o el caso de dos parejas, asentadas en el municipio de San Martín de Perapertú, que, cansados de la vida y del estrés de la ciudad decidieron poner en marcha un proyecto, en este caso sí de turismo rural, remodelando una vivienda y ofreciendo servicios de turismo activo en la comarca, aprovechando no sólo los recursos del territorio (la riqueza geológica), sino también la propia formación de estos nuevos pobladores (educadores ambientales, geólogos...).

En la provincia leonesa, en el municipio de Maraña, al sur de los Picos de Europa, nos encontramos con un matrimonio joven, también con hijos, que pusieron en marcha un conjunto de alojamientos rurales, «Las Cabañas Patagónicas», de un estilo singular, pero claramente funcionales. Otro caso a citar, entre los muchos que podemos encontrar, es el conjunto de nuevos pobladores que cambian su vida radicalmente, como ocurre con un conjunto de personas asentadas en la aldea de Las Machorras (Espinosa de los Monteros, Burgos), que abandonan por completo su vida consumista de la ciudad para iniciar un modo de vida inspirado en la soberanía alimentaria, el trueque, la reconstrucción de antiguas cabañas pasiegas...

Podríamos decir que estas son tres situaciones típicas de gente que regresa o va al campo por convicción, aunque los problemas de la educación de los hijos siempre están presentes, con tanta más fuerza cuanta menos accesibilidad tiene el lugar de residencia. Pero los ejemplos se multiplican, si bien, de momento, solo se trata de hechos cualitativos, aunque es indudable que hay profesionales que eligen este modo de vida, cuyo significado ocupacional en el ámbito rural valoraremos junto con los demás.

\section{OCUPACIÓN Y CARACTERES SOCIOECONÓMICOS DE LOS RESIDENTES Y DE LOS NUE- VOS POBLADORES}

El análisis del empleo en el ámbito rural pone de manifiesto el peso de las actividades agrarias, tanto más importantes cuanto más pequeños son los municipios. Pero, dando por sentada esta afirmación, debemos ir más allá y comprobar que no solo se trata de la elevada proporción de empleos, sino también de las dimensiones territoriales que alcanza, fenómeno que condiciona la estructura social de los pueblos y los connota y define como espacios agrarios típicos del rural profundo, frente a los que otros mantienen una personalidad económica muy diferente.

\section{La jerarquía ocupacional y territorial en los municipios rurales de Castilla y León}

En efecto, no solo se trata del hecho de que más de la mitad de los municipios regionales supera el $40 \%$ de ocupados en la agricultura, sino que esos 1.167 municipios se extienden sobre casi $40.000 \mathrm{~km}^{2}$, en los que no habita más que el $9 \%$ de la población regional, de modo que podemos identificar y delimitar como comarcas agrarias, del rural profundo, a un $41 \%$ del territorio de Castilla y León. Basta con echar un vistazo al mapa para comprobar estas afirmaciones, porque numerosísimos pueblos de las llanuras centrales y marginales y de las penillanuras encuentran en la agricultura el sector fundamental, o casi el único, de actividad económica (véase mapa figura 9). 
Ciertamente, el análisis de la estructura de la población ocupada en las áreas rurales de Castilla y León confirma que la media general supera el 20\% de ocupados en la actividad agraria, dándose su mayor concentración en las vastas llanuras de aprovechamientos agrarios extensivos, reino de los secanos cerealistas y de la ganadería de ovino: Tierra de Campos, los Cerratos y las penillanuras occidentales destacan por alcanzar los valores máximos en el empleo agrario, junto con las plataformas orientales y meridionales sorianas, además de la Tierra Llana de Ávila o La Bureba burgalesa. Es curioso comprobar el menor peso relativo de las comarcas montañosas, especialmente de las leonesas y zamoranas, aunque también de las segovianas y abulenses de la Cordillera Central, e incluso de las Montañas de Burgos.

Pero este hecho, llamativo, está estrechamente relacionado con la pérdida de entidad agraria de esas tierras, pues el vaciamiento rural ha sido de tal magnitud que el peso agrario ha caído drásticamente en favor del alcanzado por otras actividades, especialmente las relacionadas con el uso temporal del espacio, y, más concretamente, con la proliferación de servicios turísticos, de alojamientos y restaurantes, que tanto en la Cordillera Cantábrica como en la Central, o en el O de León y NO de Zamora dan empleo a más del 20\% de los ocupados. Son las dos caras de la moneda: las llanuras agrícolas se han especializado más en la agricultura, las montañas ganaderas y forestales han perdido peso en su actividad tradicional y emergen como «territorios de la diversidad funcional», basada ésta en la poquedad y escasez del empleo general y singularmente del agrario (véanse y compárense las figuras 9 y 10).

Figura 9

TASA DE OCUPADOS EN ACTIVIDADES AGRARIAS EN LOS MUNICIPIOS RURALES DE CASTILLA Y LEÓN. SEPTIEMBRE DE 2013

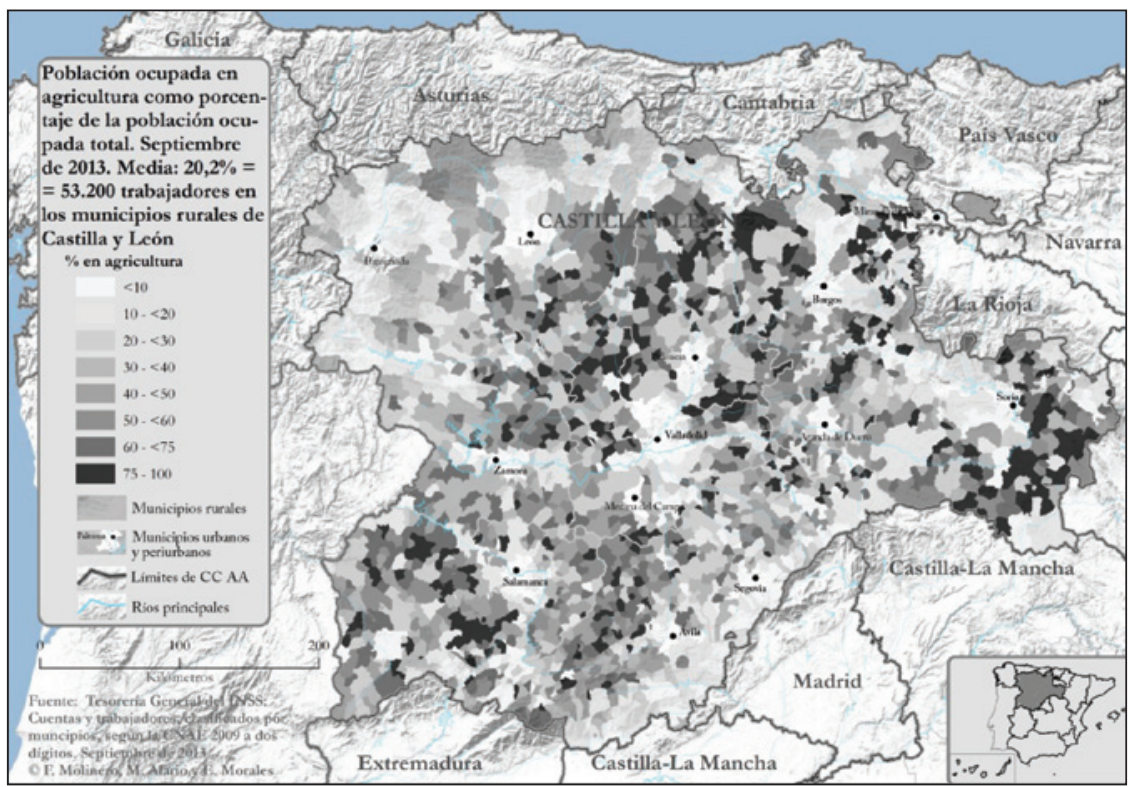






La estructura del empleo revela y confirma estas ideas, puesto que los dos tercios de los ocupados en los municipios rurales regionales lo están en agricultura, comercio y reparación, construcción, servicios turísticos e industrias alimentarias (figura 11). Hay enormes diferencias entre unas comarcas y otras, pero el peso de esos grandes rubros es general y, aunque, como hemos destacado, las montañas y las llanuras tienen comportamientos casi inversos en las actividades agrarias, en otras ramas son mucho más coincidentes. El ejemplo del comercio y reparación es ilustrativo, pues está repartido de una manera más o menos homogénea por todo el territorio, con la salvedad del papel más destacado que adquieren los centros comarcales; lo mismo sucede con las industrias agroalimentarias, cuya distribución espacial está claramente jerarquizada en torno a los centros comarcales, notándose una mayor densidad de núcleos especializados en este tipo de industrias en los regadíos del Duero, Tormes, Tierra de Pinares Segoviana y en el eje leonés de la A-6 (La Bañeza-Astorga, secundadas por Benavente en Zamora). Finalmente, la construcción muestra una distribución espacial poco homogénea, porque se concentra y densifica en las áreas más turísticas, llamando la atención los casos del NO de Zamora, en la Sanabria y el Aliste, que se continúan por los núcleos de la montaña cantábrica leonesa y que en el $\mathrm{S}$ de la región prima también a los pueblos de montaña, pero sin que se produzca una especialización clara.

Frente a estos rubros dominantes, los servicios educacionales y sanitarios muestran la misma jerarquización que las industrias agroalimentarias, aunque poco numerosos de una manera más homogénea por todos los centros comarcales. Tampoco podemos deducir tenden- 
Figura 11

ESTRUCTURA DEL EMPLEO EN CASTILLA Y LEÓN, 2013. EMPLEOS TOTALES: 263.813 RURALES Y 565.359 URBANOS Y PERIURBANOS

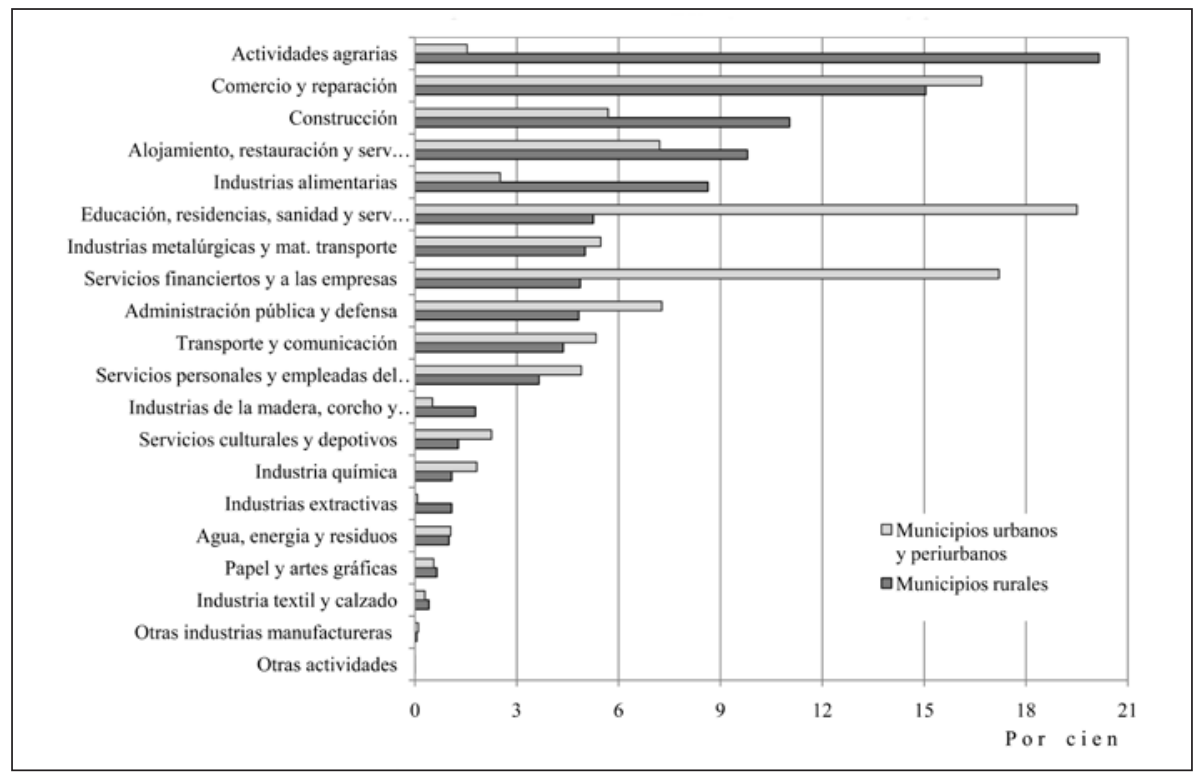

Fuente:Tesorería General del INSS, 2013. Elaboración de M. Alario, F. Molinero y E. Morales.

cias claras en otras ramas y sectores de actividad económica, pues muchas de ellas son coyunturales, azarosas o relacionadas con la existencia de algún recurso local. Este es el caso de las canteras de pizarra, o de las minas de carbón, en el O de León, o de otros recursos naturales. En toda esta dinámica, cada vez se valora más el territorio como recurso, sobre todo por tratarse de un espacio vasto y poco explotado, cuyas cualidades ambientales son cada vez más apreciadas por muchos y valoradas por muy pocos como base o asiento de un nuevo proyecto de vida.

\section{La singularidad de los nuevos pobladores en el medio rural}

Ya comentamos que, aparte de los estacionales, los nuevos pobladores, se localizan principal, aunque no exclusivamente, en las áreas de influencia de las ciudades, en las que ejercen una gama diversa de ocupaciones, relacionadas fundamentalmente con los servicios personales o culturales. Así, en los pueblos del sur de Segovia o de Ávila, abundan las granjas de caballos, que ofrecen paseos turísticos, empresas de rutas de la naturaleza, jardinería y cuidados de mascotas, deportes diversos... Esta cohorte de nuevos pobladores rurales es la más significativa en número, porque muchos de ellos viven en el campo, pero trabajan en la ciudad, caso de bastantes profesionales de la cultura o del ocio. Junto a ellos, está el caso de los nuevos pobladores de vocación rural, que, aunque poco numerosos, están creciendo. Se trata de los neorrurales, que han optado, voluntaria y conscientemente, por integrarse, vital y laboralmente, en el espacio rural. 
Los impulsos que los llevan a asentarse en el medio rural, a veces cambiando completamente sus circunstancias profesionales, económicas y sociales, son muy dispares, pero todos encuentran la razón de ser de su proyecto en la armonía con la naturaleza. Aquí hemos seleccionado 50 casos, distribuidos por todo el territorio regional, que hemos procesado para conocer las características de este nuevo grupo de neorrurales. Nos hemos basado para ello en la entrevista directa y, como resultado, podemos ver que esta llamada de lo rural afecta tanto a hombres (27 casos de la muestra) como a mujeres (23). Es evidente que los servicios constituyen el gran sector de actividad de estos nuevos pobladores, dado que más del $80 \%$ se ha integrado en él; por el contrario, solo el $14 \%$ se dedica a la actividad agraria, un $2 \%$ a la industria y otro $2 \%$ a la construcción.

Pero, dentro de los servicios, se observa una distribución expresiva, pues, salvo en los sanitarios y turísticos, las demás ramas se reparten con cierto equilibrio, aunque con más peso en el comercio. Un aspecto de interés es que las mujeres no van ni a la agricultura ni a la construcción, mientras duplican a los hombres en la rama de la administración y gestión y hay una tendencia a un cierto equilibrio en las demás (figura 12).

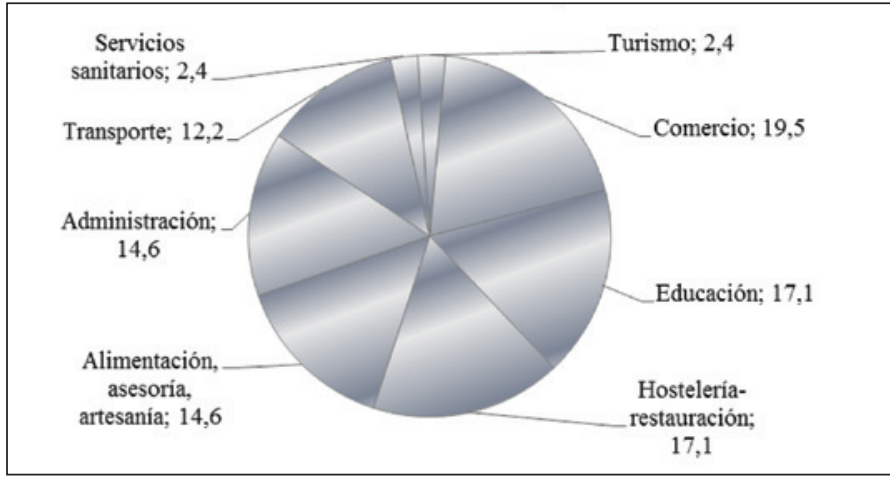

Fuente: 50 entrevistas realizadas por E. Morales, 2013.

Esta muestra de nuevos pobladores es pequeña, como pequeño es el número de casos de neorrurales, pero desde que empezó el movimiento de la vuelta al campo, con planteamientos alternativos, se han ido desarrollando diversos proyectos, algunos muy de moda en los años 1970, como el de la colonia de Barrio Panizares (Burgos). En la actualidad encontramos otros ejemplos como los de las ecoaldeas, al estilo de las de Matavenero (El Bierzo, León), Amayuelas de Abajo (Palencia, figura 13) o la anteriormente citada de Las Machorras, que, aunque no está reconocida, sus moradores llevan ese tipo de vida comentado y están dentro de lo que se conoce como BBBFarming (Big Brother Bio Farming) y otras asociaciones análogas, que se han dedicado a actividades de todo tipo, desde agricultura y ganadería ecológicas, pasando por el artesanado de la madera, del hierro y del cuero, por la elaboración de panes especiales, de mermeladas de frutas silvestres, de velas de cera natural olorosa, de quesos singulares, de construcción 


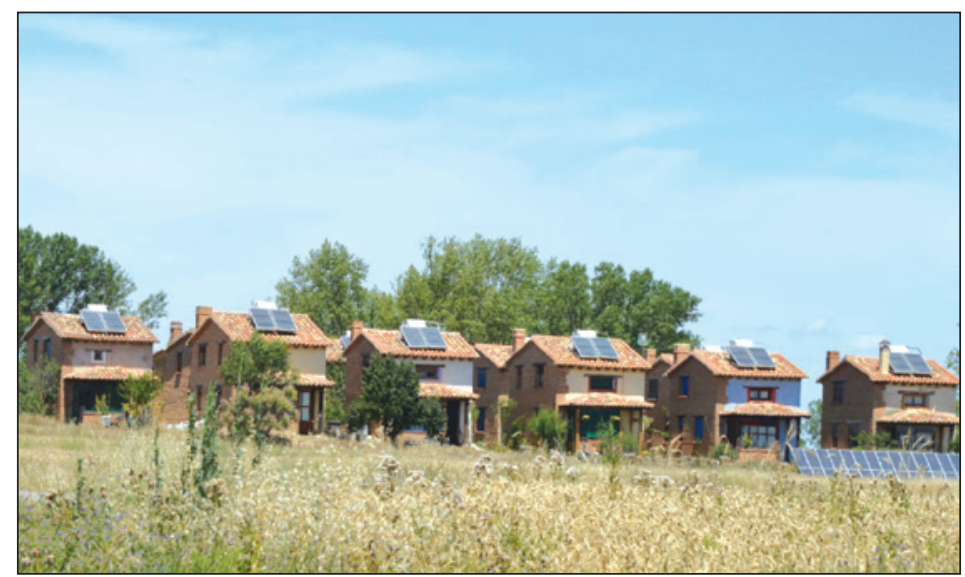

de campings y de un sinfín de actividades que en muchos casos se han consolidado y en algunos han desaparecido, pero pocos nuevos pobladores se dedican a la actividad agraria (salvo en ecológico), por cuanto todavía hay demasiada presión en el campo y no hay mercado ni siquiera para los agricultores convencionales actuales, por más que aparezcan pequeños huecos para los alternativos.

\section{CONCLUSIÓN. LOS NUEVOS POBLADORES: ENTRE LA INFLUENCIA URBANA Y LA CON- SOLIDACIÓN DE UN NUEVO PARADIGMA RURAL}

El espacio rural de Castilla y León, al igual que otros, ha conocido unas profundas transformaciones durante el último medio siglo. El éxodo rural de los años 60 y 70 acompañó a la modernización del agro, que se desestructuró completamente. Sin embargo, la pérdida de población, no se acompañó, salvo varias excepciones, de la pérdida de pueblos. La red de poblamiento, densa y dispuesta para una población mucho más numerosa, se ha mantenido y hasta ha crecido en número de unidades poblacionales.

Estos aspectos contradictorios se explican fundamentalmente por el cambio de uso del espacio rural, que, tras acometer una modernización productiva desde mediados del siglo pasado, ha conocido un proceso de especialización evidente, de modo que las antiguas llanuras cerealistas han polarizado su actividad en una agricultura cada vez más tecnificada y menos exigente en mano de obra, lo que las ha llevado a una escasa diversificación funcional y a un constreñimiento demográfico claro, tan solo salvado en algunos enclaves, franjas o «zonas» de terrenos de regadío o viñedo, más exigentes en trabajo. Por el contrario, las áreas de montaña, forestales y ganaderas, donde la actividad agraria ha tenido más problemas para adaptarse a un mercado moderno muy competitivo, han conocido no solo un vaciamiento poblacional, sino también de las explotaciones o empresas agrícolas y ganaderas que operaban antes. Han sido precisamente estas áreas montañosas las más 
beneficiadas por las nuevas actividades y nuevos usos del espacio rural. En unos casos, como en el sur de la Cordillera Central, por la proximidad a la gran urbe madrileña y el asentamiento de pobladores que viven en los pueblos y trabajan en la ciudad, o al servicio de la ciudad. En otros, por la importancia y trascendencia de la población estacional y del turismo rural. A ellos se suman los nuevos pobladores vocacionales, los neorrurales, que constituyen la punta de lanza del nuevo paradigma rural. Su significado hoy es más cualitativo que cuantitativo, pero demuestran que el campo tira y atrae, aunque hay que esperar todavía a que los nuevos paradigmas socioeconómicos y territoriales ofrezcan más y mejores posibilidades a las áreas rurales.

Entretanto, la reasignación de actividades de ocio y turismo a los espacios rurales ha conseguido mantener el poblamiento e, incluso, incrementar el número y la calidad de las construcciones, pero no ha mejorado las condiciones de vida de los habitantes permanentes de esos territorios. Surgen, así, problemas derivados de las distintas necesidades que tiene el uso temporal y el permanente del espacio. Mientras aquel requiere servicios mínimos que no pueden ser temporales, la reducción o desaparición de la población permanente conduce hacia el desmantelamiento de toda actividad y de todos los servicios, lo que acaba eliminando el atractivo rural. La tendencia actual es, por tanto, insegura, aunque creciente, en turismo, agricultura ecológica, uso temporal del espacio, artesanía y productos de calidad, hechos que pueden contribuir a la consolidación de esa tendencia.

\section{BIBLIOGRAFÍA}

ALARIO TRIGUEROS, M. (2004): «Diversificación económica en el medio rural: el turismo rural», en MOLINERO HERNANDO, F.; MAJORAL MOLINÉ, R.; GARCÍA BARTOLOMÉ, J.M. y GARCÍA FERNÁNDEZ, G. (coords.): Atlas de la España Rural. Madrid, Ministerio de Agricultura Pesca y Alimentación, pp. 355-363.

ALARIO TRIGUEROS, M. y MORALES PRIETO, E. (2012): «Nuevos pobladores, nuevas funciones, nuevos paisajes: emprendedoras y turismo rural en Castilla y León», en Investigando en rural, Actas del XVI Coloquio de Geografía Rural de Sevilla, Ulzama Ediciones, Navarra, pp. 53-62.

ALARIO, M. y BARAJA, E. (2006): «Políticas públicas de desarrollo rural en Castilla y León, ¿sostenibilidad consciente o falta de opciones?: LEADER II». Boletín de la Asociación de Geógrafos Españoles, nº 41, pp. 267-293.

ALARIO, M.; BARAJA, E. y PASCUAL, H. (2008): «Género y espacio: la inserción laboral de las mujeres rurales», en Mujeres Rurales. Estudios multidisciplinares de género, Universidad de Salamanca, pp. 61-80.

BARRIO ALISTE, J.M. del (2009 y 2010): La población de Castilla y León en los inicios del siglo XXI. Valladolid, Fundación Perspectivas de Castilla y León y Caja España (Obra Social), Informe 1/2009, en http://quedateavivir.files.wordpress.com/2010/02/informe-12009-revision-31.pdf , 200 pp. Informe 2/2010, Actualización 2010, 13 pp., disponible en http://www.leonoticias.com/adjuntos/fichero_38642_20100527.pdf

CAMARERO RIOJA, L.A. (1993): Del éxodo rural y del éxodo urbano: ocaso y renacimiento de los asentamientos rurales en España. Madrid, Ministerio de Agricultura, Pesca y Alimentación, 512 pp. 
CAMARERO, L. (Coord.), CRUZ, F.; GONZÁlEZ, M.; DEL PINO, J.A.; OLIVA, J. y SAMPEDRO, R. (2009): La población rural de España. De los desequilibrios a la sostenibilidad social. Barcelona, Obra social Fundación «la Caixa». Disponible en www. laCaixa.es/ObraSocial/

CONSEJO ECONÓMICO Y SOCIAL DE CASTILLA Y LEÓN (2012): Población y Poblamiento en Castilla y León: 1950-2010, coordinado por J.M. Delgado. Valladolid, Junta de Castilla y León, 1.026 pp.

DELGADO URRECHO, J.M. y CABALLERO FERNÁNDEZ-RUFETE, P. (Coords.) (2005): La situación de los nuevos yacimientos de empleo en Castilla y León. Valladolid, Consejo Económico y Social de Castilla y León, pp. 361-344.

GARCÍA SANZ, B. (2003): La sociedad rural de Castilla y León ante el próximo siglo. Junta de Castilla y León. Consejería de Cultura y Turismo, 417 pp.

GARCÍA SANZ, B. (2003): «¿Se acabó el éxodo rural? Nuevas dinámicas demográficas del mundo rural español», en GARCÍA PASCUAL (Coord.): La lucha contra la despoblación todavía necesaria: políticas y estrategias sobre la despoblación de las áreas rurales en el siglo XXI. Lleida, pp. 13-42.

GARCÍA SANZ, B. (2011): Ruralidad emergente, posibilidades y retos. Madrid, MARM, $538 \mathrm{pp}$.

HOMENAJE A ANTONIO MAYA FRADES (2014): De la Geografía Rural al Desarrollo Local. Universidad de León, 547 pp.

MOLINERO HERNANDO, F. (2010): «Las áreas rurales del interior de España frente al cuarto paradigma de desarrollo rural», en MAYOL, J., MUNTANER, L. Y RULLÁN, O. (eds.): Homenatge a Bartomeu Barceló i Pons, gèograf. Palma de Mallorca, Muntaner, 810 pp., cfr. pp. 441-457.

MOLINERO, F. y BARAJA, E. (2011): «Urbanización del espacio rural en Castilla y León. Transformaciones, situación y perspectivas», en GOZÁLVEZ, V. y MOLINA, M.: Urbanismo expansivo: de la utopía a la realidad. AGE-UA, Actas del XXII Congreso de Geógrafos Españoles, 814 pp., cfr. pp. 449-462.

MONREAL-BOSCH, P.; GIFRE, M. y VALLE, A. DEL (2013): «Envejeciendo en un mundo cambiante. El entorno rural una nueva realidad social. Aging in a changing world. Rural context a new social reality». Athenea Digital - 13(2), pp. 47-63.

MORALES PRIETO, E. (2010): «Las nuevas dinámicas de poblamiento en el medio rural. La llegada de nuevos pobladores en la provincia de Segovia». VIII Coloquio Ibérico de Estudios Rurales, Cáceres, 14 pp.

MORALES PRIETO, E. y ALARIO TRIGUEROS, M. (2012): «¿Se puede hablar de nuevos pobladores en un medio rural como el de Castilla y León? Los incipientes cambios en los primeros años del siglo XXI», en Investigando en rural, Actas del XVI Coloquio de Geografía Rural de Sevilla, Ulzama Ediciones, Navarra, pp. 207-216.

MORALES PRIETO, E. (2011): «Las políticas de desarrollo rural como mecanismos de actuación para el aprovechamiento de los recursos endógenos y asentamiento de población. Los casos de Tierra de Campos y Torozos». Actas del VIII Coloquio de Desarrollo Local, Baeza, 15 pp.

NOGUÉ I FONT, J. (1988): «El fenómeno neorrural». Agricultura y sociedad, nº 47, pp. 145-175. 
PALACIOS, R. y GONZÁLEZ, A. (2013): Bienvenid@ al campo. Experiencias y oportunidades en el mundo rural. Logroño, $154 \mathrm{pp}$.

SAMPEDRO GALLEGO, R. (2011): «El asentamiento de inmigrantes extranjeros en el medio rural de Castilla y León: pautas territoriales y lógicas sociales». Comunicación a Congreso, disponible en http://www.fes-web.org/uploads/files/modules/congress/11/ papers/2067.pdf

COLLANTES, F. Y PINILLA, V. (2011): «Peaceful Surrender. The depopulation of Rural Spain in the Twentieth Century (Cambridge Scholar Publishing)», 202 pp.

\section{AGRADECIMIENTOS}

Trabajo elaborado con el apoyo del Proyecto I+D+i, de Ref. CSO2012-39564-C07-01, sobre Paisajes patrimoniales de la España interior septentrional y occidental, financiado por el MINECO. 